\title{
THE RELATIONSHIP OF STATUS OF HEALTH AND ENVIRONMENTAL, SPORTS PLACES WITH AMOUNT THE MOTIVATION TO ACTIVITIES SPORTS AMONG THE STUDENTS KERMANSHAH CITY
}

\author{
Sara Almasi Chqakabod \\ Department of Physical Education and Sport Science, Kurdistan Science and Research Branch, Islamic \\ Azad University, Sanandaj, Iran \\ Khidan Hatami \\ Department of Physical Education and Sport Science, Sanandaj Branch, Islamic Azad University, \\ Sanandaj, Iran
}

\begin{abstract}
The aim of this study the relationship of status of health and environmental ,sports places with amount the motivation to activities sports among the students Kermanshah city have been. This research, applied and of descriptive statistics, inferential has been. Also the high school student's members of sports venues have constituted the statistical community and 353 of them the statistical sample. Standard questionnaire Hong Yong Lin with sampling method randomly- stratified among students distributed and by them was completed .All statistical analysis using SPSS software descriptive and inferential with test, T-Test and Pearson correlation coefficient was used. The findings suggest that the health and ecological status, sport venues had no significant relationship with the motivation of participation of students. Also Participation motivation of students by of health and ecological, venues sports was not explained.
\end{abstract}

Keywords: Sports Motivation, Students, Health, Ecological, Sports Venues

\section{INTRODUCTION}

Sports and physical education and essentially physical activity in today's world have the excellent position, not only because of the educational and health effects but also because of human's needs to movement and activity. Iran, with its population, is one of the youngest countries in the world. A large group of young people, both girls and boys are studying in universities or schools and they are considered as the countries capital. Sport and physical activity can fill lot of leisure and unemployment time of young people, especially students. Sports and physical education in terms of scientific is a new field which in many ways still traditionally followed. Although some changes in this area has been created especially in the school sports but still is far away from the global standards. Facilities and sporting venues are also not exempt from this rule (Ilkah, 2006). Sport and physical activity in today's world not only because of health and education, but also because of the need to move and activities of people enjoys a great position (Badawyet al, 2010). In fact, sports and sports activities has given special attention in the academic areas (Ball andMc Cagar, 2003). Physical and mental health, reduce medical costs, and increase production and productivity of all citizens are from the important effects of this phenomenon (kay \& Jackson, 1991). In other words, anyone at any age and physical condition can participate in sport activities (Fitz Gerald, 2005). Research carried out over the students demonstrate the fact that there is a significant difference between self-concept of athlete and non-athlete students. This means the self-concept in athlete students is more than non-athlete students (Yazdanpanah, 1992). Psychologists by following the process as describing, anticipating, and finally changing behavior are seeking to spread information and theories that enhance our understanding of human behavior in sport. For this reason, the issue of motivation is one of 
the most important issues in the field of sports psychology. In a study conducted in Denmark were known that motivation of people to participate in sports activities, is not access to high positions and access to Olympic motto (faster, higher, stronger) but health, vitality and social relationships are important reasons for participating in sports(Larsen Grad,2002). In many theories of learning, motivation cited as the most important factor in learning. Motivation to put it simply, is the direction and intensity of individual efforts (H Anshl, 2001). Motivation exists in all human activities but the amount and type are different depending on conditions. Also the sources of motivations are different depending on people. Therefore, knowledge of why some people have high motivation to achieve their goals while others are lacking the motivation depends on various factors such as gender, age, etc., Psychologists have studied motivation with certain concepts, such as competitive motivation, internal and external motivation, and hence motivation is one of the most important topics in the field of sport psychology. The motivation of contribution deals with individual differences to participate in sports activities because depending on individual differences and different sports and many environmental conditions enjoys of particular importance (Geil, 2004).all sport psychologists are believed that motivation is not a single factor to create behavior. For example, about participation in sports, various reasons, such as social interaction, fun and vitality, prevention and treatment, stress reduction, weight management, career and life relationships, health and fitness causing to tendency to exercise(Ramazani Khalil Abadi,1994).in this regard Fredrick and Ryan(1993) study indicated that the motivation of people participating in sports competition, is different with the motivation participants in sports and recreational activities( Fredrick and Ryan,1993). In competitive sports, people focus on external sources of motivation while in recreational activities, people focus more on internal motivations (hobbies, interests and skills development database)(Gail,2003). On the other hand, for many people, exercise is closely linked to the quality of the environment in which they practice. An unhealthy environment not only hurts the athlete, but also is an obstacle to individual incentives to give priority to exercise. Sports activities should be done in an environment that is favorable in terms of environmental factors. Studies show that the efficiency of respiratory tract of healthy athletes defects regularly due to exposure to polluted air. Sports researchers believe that air pollutants can adversely impact of the performance and the athlete's health in long-term. And recommended that doing sport activities and excesses be done in environments with standard sanitary conditions. Results of Tampson et al(2008), Popkin et al(2005) and Sallis et al(2000)indicated that the environmental situations of stadiums and sport halls effects the amount of presence of people in the physical activity and desirability of sport facilities in terms of environmentally will be causes to increasing participation in sports activities(Jabbari Noghabi,2011). Olympic Movement Agenda 21, explicitly emphasizes the need for environmental standards in all categories and sports spaces (Olympic Agenda 21, 2003). Sport facilities are places of comfort and health of a large number of people in the community. If the space does not meet necessary standards, and environmental standards are not observed, on the one hand will cause damage and physical risks to participants and on the other hand, the number of participants will be reduced because of unsafe environment. And thus in such a mode we will face with a sedentary society, especially exhausted and lethargic students that will have more negative complications for the country and will impose heavy costs on the government in the future. The current study by priority assessment of this subject and by considering the importance of increase and recognize the sport motivation of students, attempts to contribute to promote sport culture. Because promotion the culture of participation in the sports requires scientific knowledge of people toward sport and effective utilization of it. In this study, assessing the factors and the amount motivation of students to exercise is targeted. Thus recognize these factors and its relationship among them may provide the necessary contexts for more development of the sport. So by targeting environmental and health factors to are following to identify the factors that increase the motivation of students (primary and secondary school students in Kermanshah) to exercise and sport facilities.in fact the main purpose of this study, is the relationship between health and environmental factors of sport facilities with the motivation of sports participation of students in Kermanshah. So in this study, by has examined two aspects of the health and environmental status of sport facilities in Kermanshah with the motivation of students to carry out 
sporting activities (sports participation). A subject of sport, environment, and health and sport facilities has widely considered so that the sport has always been considered as a tool for sustainable development. The sport and health and environment have close connection with each other such that the pollutions of the environment affects the health and efficiency of people and endangers the health of the athletes. The importance of this issue is so that in 1994 the Olympic charter modified and environmental elements was added to the charter as the third element after sport and culture (Bahmanpour, 2005). Focusing health and safety issues relating to sports facilities can lead to improve the quality and quantity of sporty performance and appeal of the competition, recreational and educational activities. Also, the existence of anything that endangers the health of users of sports facilities, can be followed on legal issues and legal claims (Ghafori, 2001,Spengler et al, 2006). Many sport facilities in most parts of the Iran, the health and environmental quality was poor and it is necessary to attract the attention of athletes is low (Alizadeh, 2006). In recent years the problem of air pollution and dust also need to pay attention to the gym or indoor sports facilities has increased hundredfold. Safety component inside the sports fields, components and equipment parts, components and coatings platforms, components and component health lines such as privacy and other topics that must be addressed safety and environmental factors can lead to improve the quality and quantity of sports facilities and sports performance and fun competitions and recreational and educational activities.

Also, the existence of every reason to risk the health of users of sports facilities (observed criteria) can be followed by legal issues and legal claims. The following records can help us to achieve the desired result. Some sociologists have considered the exercise as civic religion in contemporary society (Physical Education Organization, 2002). many researchers such as Bowman \& Machuga (2001), Coetzee \& Viljoen (2002), Cox (2002), and kirkby et al(1999), Nichols et al(1999), Trembath et al(2002), Terser et al (2000) have investigated the motivation of athletes in various sports activities. They have expressed most important motivation for athletes to learn new skills, improve athletic skills available, feel the pleasure of gaining physical fitness, and enjoy healthy competition, fame and reputation. Harison \& Linch (2005) mention the motivation of athletics in sports, more internal motivations. Hoseini et al (2013) in a study, have investigated the relationship between the participation's motivation, fun and sport commitment of women participating in sports activities and resulted that there is a significant positive relationship between sport commitment and joy of sport. Fatehi \&Masrori(2013) in a study with title" Analysis of the inhibiting factors and stimulating student participation in extracurricular sports programs" have investigated the inhibiting and stimulating factors and resulted that very important priorities of inhibiting factors of participation in the sport programs are lack of access to facilities and sporting venues and lack of sports facilities, Also, escape from the routine and boring daily activities, is very motivating factor for participation in extracurricular sports programs(the same,2013). Helalizadeh et al,2007) In a study evaluated the safety situation of Iran's school sport fields and evaluated the safety situation of sport spaces as low. However, according to recent programs of Iran schools in the field of physical education, use of sports facilities by adolescent students is increasing. Sayarnejad(2008).the issues related to the safety of sport locations and spaces that sports activities are done there generally takes less attention, If the events relating to competitions and training athletes can be costly and burdensome. The dangerous items in sport field which causes to occurring injuries. But without a doubt, prevention, easier and less costly than treatment. By creating a secure environment for sports facilities users can prevent from occurring many injuries and accidents in this spaces. Soares et al (2013) by compare the contribute motivations in the sports of schools among boys and girls stated that the internal motivations causes to participation of students in the sport and entertainment and enjoy playing and being with friends should be the purpose of school sports.

Bounaman et al (2001) in a study on the Italian young's introduced the as the getting success as most important factor among the factors of motivation for participating. So it can be said that people in different communities have relatively more adhering reasons (Hashemi Cheshmi, farokhi, Zameni, 
Gravand, 2010).Petrido (2002) also in his research concluded that the lack of safety in the construction of sport facilities as well as waste and non-standard equipment, are the most reasons of causes injury of athletes. Marshal et al (2005) in their study concluded that using appropriate protective equipment's can prevent the occurrence of many sports injuries. Marshal et al(2005), Thompson et al(2008), Cowell et al(2007),Diana Para et al(2007),Baly Courti(2006),Popkin et al(2005) and Salis et al(2000) indicated that environmental situation of stadiums and sports halls will affect the level of people's participation in physical activity and desirability of sport spaces environmentally causes to increase the people's participation in sport activities. The recipes 21 of the Olympic Movement explicitly focuses on the need for environmental standards in all collection of sport spaces (Olympic Agenda 21, 1383),(Teebi et al,2011).

\section{METHODS}

Due to the nature of research, the current study is practical and descriptive and inferential statistics has used in all analysis. The population of this research includes the first and second high school students of Kermanshah city in the school year of 2015-2016. The sample of 185 males and 168353 females were determined. The sampling method was randomly-stratified. Given the nature and objectives of the research, the best option was to gather information through questionnaires. For this purpose two simultaneous questionnaires were used. The standard questionnaire (Hong-Young Lin, 2010) about the motivation for participating had four basic components including 6 items of obtain health, weigh control 4 items, happiness and joy 4 items and social interactions 4 items which totally were 18 items.(Islami et al in 2013 were confirmed the validity of the questionnaire by 12 people of sport experts)also by using Cronbach's alpha the reliability of questionnaire was obtained 0.790.and the researcher made questionnaire that was prepared by national and international standards and instructions about health, safety and environment then by selecting sport spaces in the different regions of Kermanshah city, the interested indicators were determined.in this study also for access to secondary information the library studies by searching in databases in the internet network the newest data was gathered.it should be noted that gathering information was done as presence, in order to minimize the number of returned questionnaires.

\section{FINDINGS}

In the inferential statistics by using Likert scale and quantify the opinions of respondents from qualitative to quantitative and by examine the basic hypothesis, normalizing of observations and using statistical techniques and methods such as single sample t test, F test and applying Pearson correlation coefficient. All hypothesis of research in the meaningfulness level $(p<0.0 .1)$ or $(p<0.0 .5)$ were examined. These results obtained: In order to assess the health and environmental status of sport facilities, one sample t-test was used as described in Table 1.

Table1: One sample $t$ test of environmental health and sport facilities

\begin{tabular}{|c|c|c|c|c|c|c|c}
\hline Variable & Df & $\mathrm{T}$ & $\begin{array}{c}\text { Experimental } \\
\text { Average }\end{array}$ & $\begin{array}{c}\text { Theoretical } \\
\text { Average }\end{array}$ & $\begin{array}{c}\text { Meaningful } \\
\text { Degree }\end{array}$ & $\mathrm{N}$ & Sig. \\
\hline Health & 352 & -6.955 & 3 & 1.0137 & 2.624 & 353 & 0.001 \\
\hline Safety & 352 & -13.293 & 3 & 0.939 & 2.334 & 353 & 0.001 \\
\hline Environmental & 352 & -7.223 & 3 & 1.190 & 2.509 & 353 & 0.001 \\
\hline $\begin{array}{c}\text { Health and } \\
\text { Environmental }\end{array}$ & 352 & -9.706 & 3 & 0.976 & 2.495 & 353 & 0.001 \\
\hline
\end{tabular}

As seen in Table 1, environmental health and sport facilities are equal to 2.49 and the expected average is equal to 3. The value and significance of the t-statistic is equal to 9.706 and the meaningfulness level is equal to $0.001(\mathrm{p}<0.05)$. since the value of $\mathrm{t}$ in the error level lower than 0.5 is meaningful and also the

Submit Date: 01.05.2016, Acceptance Date: 20.06.2016, DOI NO: 10.7456/1060JSE/052 
experimental average is less than theoretical average, thus it concluded that the health and environmental status of sport spaces is less than desired level. Check the status of health and environmental components of sport facilities shows that the value of $t$ in all components is negative and in the error level less than 0.05 is meaningful $(p<0.05)$.therefore we can say that health and environmental status of all components of sports facilities, significantly less than desirable level. In order to assess sport participation motivation, the one-sample $t$ test was used, table2.

Table2: Single sample t test motivation for sport participation

\begin{tabular}{|c|c|c|c|c|c|c|c}
\hline Variable & Df & $\mathrm{T}$ & $\begin{array}{c}\text { Experimental } \\
\text { Average }\end{array}$ & $\begin{array}{c}\text { Theoretical } \\
\text { Average }\end{array}$ & $\begin{array}{c}\text { Meaningful } \\
\text { Degree }\end{array}$ & $\mathrm{N}$ & Sig. \\
\hline Obtain Health & 352 & 36.937 & 3 & 0.702 & 4.383 & 353 & 0.001 \\
\hline Weight Control & 352 & 25.960 & 3 & 0.764 & 4.058 & 353 & 0.001 \\
\hline $\begin{array}{c}\text { Happiness and } \\
\text { Joy }\end{array}$ & 352 & 11.965 & 3 & 1.032 & 3.658 & 353 & 0.001 \\
\hline $\begin{array}{c}\text { Social } \\
\text { Interaction }\end{array}$ & 352 & 14.621 & 3 & 1.103 & 3.860 & 353 & 0.001 \\
\hline
\end{tabular}

As it seen in table2, The motivation of participation in sport was equal to 4.03 and the expected average was equal to 3 .the amount of t statistic was equal to 32.861 and the obtained meaningfulness level was reported $0.001(p<0.05)$ since the value of $t$ is meaningful in the error level of less than 0.05 and also the experimental average is more than theoretical average. Thus it concluded that the motivation to sport participation is significantly higher than desired level. Examine the status of components of sport participation motivation shows that the amount of $t$ in all components is positive and in the error level less than 0.05 is meaningful. $(\mathrm{p}<0.05)$.thus it can be said that the status of all motivational aspects of sport is meaningfully higher than desired level. For examine the relationship between health and environmental factors with the amount of motivational sport participation the Pearson correlation Coefficient has used. Table 3.

Table 3: Pearson correlation coefficients between health and environmental factors of the motivation for sport participation

\begin{tabular}{|c|c|c|c|c|c|}
\hline & 1 & 2 & 3 & 4 & 5 \\
\hline Health & 1 & & & & \\
\hline Safety & $0.86^{* *}$ & 1 & & & \\
\hline Environmental & $0.78^{* * *}$ & $0.78^{* * *}$ & 1 & & \\
\hline Health and Environmental & $0.94^{* *}$ & $0.93^{* *}$ & $0.92^{* *}$ & 1 & \\
\hline Motivational Participation & -0.00 & -0.02 & -0.05 & -0.02 & 1 \\
\hline
\end{tabular}

Correlation is significant in the $1 \%$ level (bilateral) * Correlation is significant in the $5 \%$ level (two-way)

Results of table 3 shows that the health factor $(\mathrm{R}=-.00)$, safety $(\mathrm{R}=-.02)$, environment $(\mathrm{R}=-.05)$ and Health and environmental $(\mathrm{R}=-.02)$ have no meaningful relationship with amount of motivation for sport participation. For determine effect of every health and environment factors of sport places as predict variables with the motivation of sport participation as a control variable, all variables were entered to the regression equation that its results indicated in the following table.

Table4: Multiple regression analysis between predictor and the criterion variables

\begin{tabular}{|c|c|c|c|c|c|c|c|c|}
\hline $\begin{array}{c}\text { Source } \\
\text { Variance }\end{array}$ & $\begin{array}{c}\text { Sum Of } \\
\text { Squares }\end{array}$ & Df & $\begin{array}{c}\text { Mean of } \\
\text { Squares }\end{array}$ & F & $\begin{array}{c}\text { Significant } \\
\text { Level }\end{array}$ & R & $\begin{array}{c}\text { Adjusted } \\
\text { R 2 }\end{array}$ & SE \\
\hline Regression & 24.597 & 3 & 71.532 & 0.631 & 0.595 & 0.074 & -0.003 & 10.64 \\
\hline Rest & 39.725 & 347 & 113.287 & & & & ${ }^{2} \mathrm{R}$ & \\
\hline
\end{tabular}

Submit Date: 01.05.2016, Acceptance Date: 20.06.2016, DOI NO: 10.7456/1060JSE/052 Copyright (C) The Turkish Online Journal of Design, Art and Communication 


\begin{tabular}{|l|l|l|l|l|l|l|l|} 
All & 39.323 & 350 & & & & & 0.005
\end{tabular}

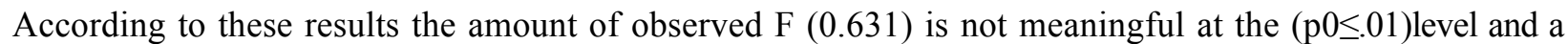
percentage of variance is related to motivation of sport participation not determined by using components of health and environment factors $\left(\mathrm{R}^{2}=-0.003\right)$.

Table 5: Coefficients of predict equation of the motivation of sports participation by health and environmental factors

\begin{tabular}{|c|c|c|c|c|c|}
\hline Model & B & Standard Error & $\beta$ & T & Meaningfulness \\
\hline The Fixed Value & 72.784 & 1.607 & & 45.297 & 0.000 \\
\hline Health & 0.115 & 0.130 & 0.099 & 0.847 & 0.337 \\
\hline Safety & -0.014 & 0.155 & -0.010 & 0.091 & 0.928 \\
\hline Environmental & -0.129 & 0.102 & -0.116 & -1.266 & 0.207 \\
\hline
\end{tabular}

Regression coefficients for each health and environmental factors as predictive variables shows that none of the components of positional factors $(\mathrm{P} 0 \leq .000)$ cannot explain the variance of criterion variable, that is the motivation for sport participation significantly,

\section{DISCUSSION AND CONCLUSIONS}

The main purpose of this study, was examine the relationship between health and environmental factors of sporting venues with sports participation motivation of the first and second course students in Kermanshah. The results of the desirability of health and environment status of sport space of Kermanshah showed that it was significantly less than desired level. This study was consistent with studies of Helalizadeh et al (2007), Sayah and Arab Ameri (2004), Farsi (2006), Sayarnejad (2008).Marshal et al (2005)in their research concluded that using proper protective equipment can prevent the occurrence of many sports injuries. And Petrido(2002) in his study concluded that the lack of safety in the construction of sport facilities as well as waste and non-standard equipment, causes of injury to athletes. But the favorable review of the amount of sports participation motivation of students of Kermanshah indicated motivation condition for sport participation is significantly higher than desirable level. As well as investigation of motivational factors sports participation showed that the status of all aspects of sports participation motivation, significantly higher than the desired level. The results were consistent with results of Hoseini et al(2013) and many researchers such as Bowman \& machuga(2001), Coetzee \& Viljoen(2002), Cox(2002), Kirkby et al(1999),Nicolz et al(1999), Trembath et al(2002), Treasure et al(2008).and it was inconsistent with Fatehi Masror(2013),Harison and Linch(2005).many comments of researchers in line with these findings, knew the most important motivations of athletes learning new skills, improving sport skills, feel the pleasure of physical preparation, Enjoy healthy competition and obtain fame and reputation. The findings in relation to the main hypothesis of this study showed that there was no meaningful relationship between health's, safety, environmental factors with amount of motivation to sport participation. The result of this finding was not consistent with results of studies of Tompson et al(2008),Kawl et al(2007),Diana et al(2007),Baely Korti(2006),Popkin et al(2005) and Salis et al(2000).given that the inconsistent studies was in relation with all citizens thus we can say that finding of this research which had been about students may be logical. Because the student is further go under the influence of motivational factors contribute to the cause of health, weight control agent, the agent of social interaction and the joy and pleasure. And paid less attention to other factors. Harrison and Lynch (2005) know the motivation of athletes are more internal motivations. Despite the shortcomings of sport facilities probably internal motivations or some external motives (championship and gaining membership in the national team and professional reputation ...) and for the better future, they realized this places. The findings also showed that each of health and environmental factors of sport places as predictable variables with having sport participation motivation as criterion variable was not explained 
with\%99 confidence, thus it is necessary to find other predictable variables.( Researcher In the future research, will be follow up the issue ).the predictor variable can be obtaining fame and championship, be professional, obtain health and control weight, fitness or, releasing energy, self-concept, began studying physical education at the tertiary level are other variables. The environment issue of sport places of Kermanshah have been the most concerns of students. The status of more sport places in terms of health have more proper status in comparison with safety and environmental items. Perhaps the absence of professional managers in the maintenance of sport facilities and lack of sufficient budget allocation for this affairs. Therefore for prevent of occurrence from adverse events and accidences and favor maintenance of sport places it is recommended that expert people be employed in this places.as well as the sufficient budget allocate for related affairs and managers spend the budgets optimally. Unfortunately, due to lack of awareness and proper management has observed that some non-professional managers, not spending funds allocated and the status of sport space becomes more adverse every day. Another problem than cannot be latent from the view of sport coaches and students is constructing sport places that is done generally by unaware experts. Thus it is recommended that the planning managers of the country make decisions about this issue and create academic fields for training experts in the engineering construction of sport spaces to the sport places that are built with great budget be matched with global standards. While these professionals can also be used for repair and maintenance of sport facilities. Finally the researcher wants from another researches to do similar researches in the sport facilities of Education \& Training of other provinces and cities.

\section{REFERENCES}

Alizadeh, Mohammad, Farsi, Alireza, Persian, Cyrus, and mozafari, A. (2007). Safety check the status of sport facilities Tehran state universities and provide appropriate solutions. Research in Sport Science, XV, 83.

Anshl, Mark. (2001) .rvanshnasy exercise from theory to practice, translated by Ali Asghar Mosaddad, Tehran 1380 All Press.

Badawy B, Anani T, Mohamed El-Sayed M, 2010. Establishing an achievement motivation scale for specialists of the sport for all.World Journal of Sport Sciences, 3(2), 181-185.

Ball G, McCagar L. (2003). Childhood obesity in Canada: a review of prevalence estimates and risk factors for cardiovascular diseases and type 2 diabetes. Canadian Journal of Applied Physiology, 28(2), 432-447.

Fitzgerald M. (2005). Leisure activities of school children. Journal of Adolescence, 32(2), 165-184.

Forough Fattahi Masrur, Forouzan Fattahi Masrur, Rasool Norouzi Seyed Hossini, Seyed Ali. (2014). Analysis of Preventive and Motivating Factors of Students' Participation in Extracurricular Sports Programs, International Journal of Sport Studies. Vol., 4 (3), 343-347.

Frederick, C.M, Ryan, R.M. (1993). Differences in motivation for sport and exercise and their relations with participation and mental health. Journal of Sport Behavior, 16: 124-146.

GHAFOURI, Ali, explorer, M; Dehkhoda, Muhammad, Arabs Ameri, E. (2001). The frequency of the incidence of sports injuries in student Olympiads public universities and cultivate medicine in the summer of 2000, 40, 34-43.

Ghafuri, F. (2005), "the role of the social demand for strategy-making exercise" of the sport. Alizadeh, M. et al., increase productivity practices as review sites, facilities, sports equipment, Journal of Sport Sciences, 11.

Gill, D.L. (2000). Psychological dynamics of sport and exercise. Journal of Human Kinetics. Vol.2: 112118.

Helalizadeh, M, farsi, AR, sayah, M. rasekh, Nazanin; Darabi, Hodjattallah. (2007). The situation for sport fields in schools and provide appropriate solutions. Journal of Sports Sciences, XVI, 54.

Submit Date: 01.05.2016, Acceptance Date: 20.06.2016, DOI NO: 10.7456/1060JSE/052

Copyright (C) The Turkish Online Journal of Design, Art and Communication 
Kay T, Jackson G. (1991). Leisure despite constraint: the impact of leisure constraints on leisure participation. Journal of Leisure Research, 23(6), 981-993.

Khosravi, R. (2011). The relationship between environmental health and sport facilities with the participation of citizens in physical activity Khorasan, Proceedings of the Sixth National Conference on Physical Education and Sport Sciences students.

Mozaffari, AA. (2009). Design and management of facilities and sporting venues. Tehran: Institute of Physical Education and Sport Sciences, First Edition.

Noorbakhsh, parivash, mazarehi, E. (2006), "The motivation of students and male athletes in sports" Olympic Magazine, 2 (34) summer.

Petrido, E., Sibert, J., Dedoukou, X., Skalkidis, I., \& Trichopoulos, D. (2002). Injuries in public and private playgrounds: the relative contribution of structural, equipment and human factors. Acta Paediatr, 91:691-697.

Physical Education Organization of Iran. (2002), "outline a comprehensive system of physical education and sports development strategy document" Co-Rad system.

Popkin .Barry M, Kiyah Duffey, Penny Gordon-Larsen. (2005). Environmental influences on food choice,physical activity and energy balance. Physiology \& Behavior 86 2005) 603-613.

Ramezani Khaliabad, G. (1994). The motivation of people participating in sport in Tehran. MSc thesis, Tarbiat Moallem University of Tehran.

Roderick, LM. (2004). the ergonomics of children in playground equipment safety. J ournal of Safety Research, 35(3):249-254.

Sallis, J.F., Prochaska, J.J., Taylor, W.C. (2000). A review of correlates of physical activity of children and adolescents. Medicine and Science in Sports and Exercise 32, 963.

Sayyah, M., and Arab Ameri, elahe. (2004). sport facilities safety situation in Kashan. Tehran: Congress on Safety City.

Spenngler, J. O., Connaughton, D. P., Pittman, A. T. (2006). Risk management in sport and recreation. Human Kinetics. pp. 101-112.

Tayebi, M. (2011). Investigate the relationship between the environmental situation with the level of participation in physical activity and sports spaces, the first National Conference on Sports Tourism Development and Management, University of Arad, shahrood Branch.

Thomson $\mathrm{C}$ atharine, association between characteristics of neighborhood open space and older people, $\mathrm{s}$ walking. (2008). journal of urban forestry \& urban Greening, 7,41-51 